\title{
Knowledge of Local Anesthetic Systemic Toxicity among Emergency Medicine Physicians: A Cross-Sectional Study
}

\author{
Buğra İLHAN ${ }^{1, *}$, Mehmet Cihat DEMİR ${ }^{2}$
}

\author{
${ }^{1}$ Department of Emergency Medicine, \\ University of Health Sciences, Bakırköy \\ Dr. Sadi Konuk Training and Research \\ Hospital, İstanbul, Turkey \\ ${ }^{2}$ Department of Emergency Medicine, \\ Düzce University School of Medicine, \\ Düzce, Turkey
}

\section{*Correspondence}

bugra_ilhan@yahoo.com

(Buğra İLHAN)

\begin{abstract}
Background: Local anesthetics (LAs) are widely used in medical practice. The prevalence of LAs used has attracted attention with increasing reports of toxicity. To our knowledge, there is no study that surveyed emergency medicine physicians (EMPs) about local anesthetic systemic toxicity (LAST). We aimed to assess EMPs' knowledge and awareness of LAST. Methods: This was a cross-sectional questionnaire-based study. EMPs working in the emergency department of a variety of hospitals (university, training and research, public, private) in Turkey participated in the study via e-mail. EMPs who did not use LAs and residents were excluded. The questionnaire was sent to physicians via e-mail, and responses were analyzed. Results: A total of 178 EMPs participated in the study and $20.8 \%$ and $22.5 \%$ of respondents recognized all the symptoms and treatment options of LAST respectively. About $4 \%$ had no knowledge on intravenous lipid emulsion (ILE) treatment, $41.6 \%$ used ILE treatment, and $42.1 \%$ were correct in the treatment dose of ILE. A significant correlation was found between the type of hospital and related training and the correct response of the ILE dose. Participants working at a university hospital had significantly higher correct answers $(58.3 \%)$ on the treatment dose of ILE, but the correlation was weak (r: 0.165). Conclusion: Although LAST might have high mortality and morbidity in emergency patients, the level of EMPs' knowledge and awareness of LAST is poor. The current training about LAs should be increased and standardized. EMPs should be encouraged to use ILE if indicated.
\end{abstract}

\section{Keywords}

Local anesthetics, Systemic toxicity, Emergency medicine physicians, Intravenous lipid emulsion

\section{Introduction}

Local anesthetics (LAs) cause temporary loss of sensation in the applied area and make the procedure comfortable for both the patient and physician. LAs are widely used in many clinical situations and side effects and toxicity are also common. In the 1880 s, with the introduction of cocaine into clinical practice, local anesthetic systemic toxicity (LAST) were first reported. Guidelines published in 2010 by The American Society of Regional Anesthesia and Pain Medicine and the Association of Anaesthetists of Great Britain and Ireland made recommendations for LAST prevention, diagnosis, and treatment $[1,2]$. In these guidelines, intravenous lipid emulsion (ILE) treatment is a treatment recommendation.

LAST can cause mild and temporary symptoms but can also lead to life-threatening conditions and death. The incidence of LAST ranges from 1 to 111 cases per 10.000 [3]. Complications are more common in the pediatric and geriatric age groups, those with liver or heart failure and those with cardiac conduction disorders [2-4]. Dose reduction, test dose administration, incremental injection, negative aspiration, preferring less toxic agents, and ultrasound-guided intervention are recommended to avoid LAST [2,3].

LAST is usually diagnosed by recognizing the clinical conditions seen after drug administration because LAs blood levels cannot be measured in most clinics [3]. The effects on the cardiovascular system (hypertension, tachycardia, ventricular arrhythmias, hypotension, bradycardia, conduction disorders, and asystole) following central nervous system effects (auditory disturbances, circumoral numbness, metallic taste, agitation, seizures, and coma) constitute the typical presentation of LAST $[2,3]$. However, it has been reported that $40 \%$ of cases may involve atypical presentations [2]. Also, approximately 1 in 3 LAST cases are associated with brain injury and death [5]. Airway management and oxygenation to protect the patient from hypoxia and acidosis are essential. Benzodiazepines (lipid emulsion or small doses of propofol if benzodiazepines are not available) are recommended if seizures occur [2]. Also, it is recommended that ILE treatment should be started as soon as the first signs of LAST are seen [1-4]. 
TA B L E 1. Demographic data and responses to the use of local anesthetics.

\begin{tabular}{|c|c|}
\hline Female, $\mathrm{n}(\%)$ & $68(38.2)$ \\
\hline Age (years), median (min-max) & $36(30-63)$ \\
\hline Total working time in ED (years), median (min-max) & $10(3-35)$ \\
\hline Total working time as a specialist (years), median (min-max) & $4(1-25)$ \\
\hline \multicolumn{2}{|l|}{ Institution type, $\mathrm{n}(\%)$} \\
\hline Public hospital & $67(37.6)$ \\
\hline Training and Research hospital & $60(33.7)$ \\
\hline University hospital & $36(20.2)$ \\
\hline Private hospital & $15(8.4)$ \\
\hline \multicolumn{2}{|l|}{ Use of local anesthetics, $\mathrm{n}(\%)$} \\
\hline Lidocaine & $141(79.2)$ \\
\hline Prilocaine & $161(90.4)$ \\
\hline Bupivacaine & $25(14.0)$ \\
\hline Lidocaine + Prilocaine & $101(56.7)$ \\
\hline Lidocaine + Bupivacaine & $2(1.1)$ \\
\hline Lidocaine + Prilocaine + Bupivacaine & $23(12.9)$ \\
\hline Alone & $165(92.7)$ \\
\hline With adrenaline & $51(28.7)$ \\
\hline Alone and with adrenaline & $38(21.3)$ \\
\hline Intravenous & $23(12.9)$ \\
\hline Subcutaneous & $149(83.7)$ \\
\hline Intramuscular & $46(25.8)$ \\
\hline Topical & $92(51.7)$ \\
\hline Intranasal & $12(6.7)$ \\
\hline Intraarticular & $14(7.9)$ \\
\hline Minor procedure & $178(100.0)$ \\
\hline Regional block & $87(48.9)$ \\
\hline Every day & $108(60.7)$ \\
\hline$\geq 2 /$ week & $40(22.5)$ \\
\hline 1/week & $23(12.9)$ \\
\hline $1 /$ month & $5(2.8)$ \\
\hline$<12 /$ year & $2(1.1)$ \\
\hline \multicolumn{2}{|l|}{ Interventions to prevent toxicity, $\mathrm{n}(\%)$} \\
\hline Ultrasound guided & $29(16.3)$ \\
\hline Negative aspiration & $105(59.0)$ \\
\hline Test dose & $10(5.6)$ \\
\hline Incremental injection & $56(31.5)$ \\
\hline With adrenaline & $13(7.3)$ \\
\hline Nothing & $41(23.0)$ \\
\hline
\end{tabular}

ED: Emergency department.

Every LA procedure carries the risk of LAST. The frequency of LAs usage in busy clinics, such as emergency departments, is high. To our knowledge, there are no previous studies that have evaluated the knowledge and awareness of emergency medicine physicians (EMPs) about LAST. The primary objective of this study is to assess EMPs' level of knowledge and awareness of LAST.

\section{Methods}


TA B L E 2. Recognition of symptoms and treatment options of LAST by EMPs.

\begin{tabular}{lc} 
Symptoms of LAST, $\mathbf{n}(\mathbf{\%})$ & $142(79.8)$ \\
\hline Allergy/Anaphylaxis & $76(42.7)$ \\
\hline Metalic taste & $94(52.8)$ \\
\hline Circumoral numbness & $96(53.9)$ \\
\hline Dizziness & $81(45.5)$ \\
\hline Tinnitus & $133(74.7)$ \\
\hline Loss of consciousness & $115(64.6)$ \\
\hline Seizure & $162(91.0)$ \\
\hline Arrhythmia & $163(91.6)$ \\
\hline Hypotension & $157(88.2)$ \\
\hline Cardiovascular collaps & $37(20.8)$ \\
\hline Recognizing all the symptoms of LAST & \\
\hline Treatment options of LAST, n (\%) & $145(81.5)$ \\
\hline Symptomatic & $99(55.6)$ \\
\hline Antihistamines & $77(43.3)$ \\
\hline Methylene blue & $139(78.1)$ \\
\hline ILE & $132(74.2)$ \\
\hline Resuscitation & $40(22.5)$ \\
\hline Recognizing all treatment options of LAST & Intravenous lipid emulsion, EMPs: Emergency Medicine \\
\hline PAST: Local anesthetic systemic toxicity, ILE: & \\
\hline
\end{tabular}

T A B L E 3. The relationship between correct answers and type of hospital, frequency of LAs usage and educational status.

\begin{tabular}{|c|c|c|c|c|c|c|}
\hline & \multicolumn{2}{|c|}{ LAST symptoms } & \multicolumn{2}{|c|}{ LAST treatment } & \multicolumn{2}{|c|}{ ILE dose } \\
\hline & $\mathrm{C}^{1}$ & $\mathrm{p}$ & $\mathrm{C}^{2}$ & $\mathrm{p}$ & $\mathrm{C}^{3}$ & $\mathrm{p}$ \\
\hline \multicolumn{7}{|l|}{ Instution type, n (\%) } \\
\hline Public & $15(22.4)$ & 0.306 & $17(25.4)$ & 0.41 & $20(29.9)$ & 0.024 \\
\hline Training and Research & $13(21.7)$ & & $13(21.7)$ & & $29(48.3)$ & $0.165^{*}$ \\
\hline University & $4(11.1)$ & & $5(13.9)$ & & $21(58.3)$ & \\
\hline Private & $5(33.3)$ & & $5(33.3)$ & & $5(33.3)$ & \\
\hline \multicolumn{7}{|c|}{ Frequency of LAs use, n (\%) } \\
\hline Everyday & $18(16.7)$ & 0.374 & $20(18.5)$ & 0.217 & $48(44.4)$ & 0.811 \\
\hline $2 / w$ & $11(27.5)$ & & $13(32.5)$ & & $17(42.5)$ & \\
\hline $1 / w$ & $6(26.1)$ & & $6(26.1)$ & & $7(30.4)$ & \\
\hline $1 / \mathrm{m}$ & $2(40.0)$ & & $0(0.0)$ & & $2(40.0)$ & \\
\hline$<12 / y$ & $0(0.0)$ & & $1(50.0)$ & & $1(50.0)$ & \\
\hline \multicolumn{7}{|l|}{ Education on LAs, n (\%) } \\
\hline Yes & $21(23.6)$ & 0.453 & $22(24.7)$ & 0.724 & $44(49.4)$ & 0.142 \\
\hline No & $9(22.0)$ & & $9(22.0)$ & & $14(34.1)$ & \\
\hline Do not remember & $7(14.6)$ & & $9(18.8)$ & & $17(35.4)$ & \\
\hline
\end{tabular}

\subsection{Study Design}

This was a cross-sectional questionnaire-based study. After the approval of the local ethics committee (2019/143), physicians working in the emergency department (ED) between 1 April 2019 and 31 August 2019 were included. Informed consent 
for the study was obtained. Physicians who did not use LAs in their daily practice and residents were excluded from the study. The questions were selected after a review of the literature and were based on similar studies [6-9]. The questionnaire was designed in 3 sections. Section 1 included demographic information, institution information, and years of professional experience. Section 2 asked about LA usage practices, frequencies, and interventions preferences to prevent toxicity. In section 3 knowledge and experiences in the diagnosis and treatment of LAST and ILE treatment were questioned. The questionnaire form was piloted with 20 EMPs to evaluate scope and clarity and minor changes were made. The responses of these 20 participants were not included in the analysis.

\subsection{Data Collection}

Taking Karasu et al.'s study as a reference, the sample size was calculated as 162 with the use of an $80 \%$ power and $\alpha=0.05$ [6]. Questionnaire forms were sent to 690 physicians by email, and responses were received from 297 physicians. A total of 119 were excluded (59 EMPs who did not use LAs and 60 residents). A total of 178 EMPs' responses were recorded and analyzed. The flow diagram of the study was shown in Fig. 1.

\subsection{Data Analysis}

Descriptive statistics were presented in numbers and percentages. Numerical variables were summarized with mean \pm standard deviation or median (min-max). Pearson's chi-square test and Fisher's exact test (when the expected number was less than 5) were used for categorical variables. Statistical analyses were performed using IBM SPSS for Windows version 21. p $<0.05$ was considered significant.

\section{Results}

A total of 178 responses were included in the study. The median age of the participants was 36 (30 - 63), and $68(38.2 \%)$ were women. A total of $64.6 \%$ of the participants were in the first five years of practice. Demographic information and LAs usage practices of the participants are shown in Table 1.

A total of $10(5.6 \%)$ of the participants answered all of the questions about LAST symptoms, treatment, and ILE dose correctly. For LAST symptoms and treatment the number of participants who answered correctly were 37 (20.8\%) and 40 $(22.5 \%)$ respectively. Thirty-two (18\%) of the participants previously encountered LAST, and 157 (88.2\%) said they could treat LAST. Also, $136(76.4 \%)$ responded that they knew how to administer LAST treatment. While the success rates and LAST experience were low, the self-confidence of the EMPs about LAST treatment was higher. Also, there was no significant relationship between years of professional experience or years of experience as a specialist and knowing LAST symptoms, treatment, and ILE treatment dose correctly $(p>0.05)$. The responses of EMPs regarding which symptoms they consider as LAST symptoms and which drugs should be used in the treatment of LAST are shown in Table 2.

There was a significant relationship between the type of hospital in which the participants worked and the correct response to the treatment dose of ILE $(p=0.024)$. The partici- pants working at University or Training and Research hospitals had higher correct answers to the ILE treatment dose, but the correlation was weak (r: 0.165$)$. Only $89(50 \%)$ of the participants stated that they received training on LAs. The rates of participants who received training on LAs were 30 (44.8\%) for the public hospitals, $28(46.7 \%)$ for training and research hospitals, 27 (75.0\%) for university hospitals, and 4 (26.7\%) for private hospitals. There was a significant relationship between the type of hospital in which the participants worked and having been educated about LAs $(p=0.011)$. The relationship between the type of hospital, frequency of LAs use, education level, and correctly answered questions are shown in Table 3.

The majority of the participants, $124(69.7 \%)$ did not calculate the pre-procedure dose and $120(67.4 \%)$ did not calculate the pre-procedure doses in patients with additional comorbidity. A total of $74(41.6 \%)$ of the participants did not know the max dose of LAs that they used, and 59 (33.1\%) did not know the dosage and concentration of the LA drug. A total of $41(23 \%)$ of the participants did not take any precautions to prevent toxicity, and $130(73 \%)$ did not discuss the risks associated with LAST with their patients before the procedure, or obtain informed consent.

For the questions about ILE treatment, $142(79.8 \%)$ of the participants stated that ILE treatment could be used in LAST treatment, $73(41.0 \%)$ stated that they have ILE in their clinics, and $96(53.9 \%)$ stated that their hospital pharmacies have ILE. The remainder said ILE is not available in their clinics and pharmacies, or they don't know. The answers to the questions about ILE treatment are shown in Table 4.

\section{Discussion}

This study found a low level of knowledge and awareness of LAST among EMPs. Only $20.8 \%$ of the participants answered all the symptoms of LAST correctly. Life-threatening conditions are identified to a great extent, but early signs of LAST are less well recognized. Similarly to Collins, Karasu et al., and Urfalıoglu et al.'s studies, we found higher rates of arrhythmia, hypotension, and cardiovascular collapse for LAST symptoms [6, 9, 10]. A large number of participants recognized LAST treatment options but only $22.5 \%$ correctly answered all of the questions related to treatment options. This implies a severe problem with the early diagnosis of LAST and the immediate initiation of treatment for potentially life-threatening conditions. Compared to Karasu et al. and Urfalığlu et al.'s studies, Nonetheless, the number of participants who correctly answered questions about symptoms and treatment options were higher than in other published studies $[6,9]$. Most of the toxicology cases are seen in the ED compared to other departments that may account for higher knowledge and awareness [11-13]. EMPs' correct response rates were higher than other studies, but still disappointing.

Similar to our study, studies by Urfalığlu et al. and Karasu et al. showed no significant difference between the years of professional experience and training $[6,9]$. They found a low level of knowledge and awareness, similarly to our study. The majority $(64.6 \%)$ of the participants in this study were in the first five years of their practice, while almost half had more than ten years of experience in Oksuz et al.'s study [7]. Also, 
TA B L E 4. Responses to ILE treatment.

\begin{tabular}{lc} 
Have you heard of ILE treatment? $\mathbf{n}(\%)$ & $7(3.9)$ \\
\hline Never heard of it & $26(14.6)$ \\
\hline I have heard of it but I can't recall & $41(23.0)$ \\
\hline I have read a scientific paper on it & $104(58.4)$ \\
\hline I know when and how it is used & $75(42.1)$ \\
\hline ILE treatment dose, $\mathbf{n}(\%)$ & \\
\hline $1.5 \mathrm{ml} / \mathrm{kg}$ IV bolus, $0.25 \mathrm{ml} / \mathrm{kg} / \mathrm{min}$ IV infusion & $104(58.4)$ \\
\hline Have you ever used ILE? $\mathbf{n}(\%)$ & $16(9.0)$ \\
\hline No & $64(36.0)$ \\
\hline Yes, I have used to treat LAST & $6(3.4)$ \\
\hline Yes, I have used to treat another toxicity except LAST & \\
\hline Yes, I have used to treat both LAST and another toxicity &
\end{tabular}

ILE: Intravenous lipid emulsion, LAST: Local anesthetic systemic toxicity.

in our study, no significant relationship was found between total working time in the ED, duration of work as a specialist, and correct response to recognizing the symptoms, treatment options, and treatment dose of ILE. We conclude that the years of experience in ED do not contribute to LAST knowledge levels, awareness, and training.

Training on LAs in university hospitals was higher than in other hospitals. We found a significant correlation between the type of hospital and training and answering the dose of ILE correctly. This result can be explained by the fact that severe LAST cases are frequently referred to university hospitals, as tertiary care hospitals. Also, ILE treatment is used to treat other severe toxicity cases that adds to experience and knowledge. Also, continuing medical education in university hospitals is more widely available and can account for these differences.

As in our study, Karasu et al. and Urfalioglu et al.'s studies showed that the participants most frequently use LAs "Every day", and that training rates are low $19.8 \%$ and $28.8 \%$, respectively [6, 9]. However, EMPs are using more LAs, receiving more training, and answering the LAST symptoms, treatment, and ILE dose correctly more often. Although education is essential for LAST, we found no significant relationship between training status or the frequency of use of LAs and correctly answering the LAST symptoms, treatment, and ILE dose. We conclude that the duration, quality, and content of the LAs training given in the national ED residency program is not sufficient.

In the study by Karasu et al., the non-anesthesiology residents' training rate related to LAST was found to be less than that of anesthesiologists [6]. Also, in Sagir et al.'s study, they report less knowledge and awareness for LAST among nonanesthesiology residents. In our study, EMPs training rate was higher than in other studies, but not sufficient. Every clinic which uses LAs should learn and manage LAST, especially the ED, because LAST cases will ultimately be referred to the ED.

We found that LAs were mostly used as single agents with bupivacaine the least preferred choice. This is in contrast to Urfalıglu et al.'s study among ophthalmologists [9]. In ED practice, minor short-term procedures were common (the LAs usage rate for minor procedures was $100 \%$ ). For this reason, LAs agents which have a long duration of action, narrow therapeutic window, and high risk of toxicity, like bupivacaine, were chosen less by the EMPs. Also, the subcutaneous route was the most common method similar to the findings in Karasu et al.'s study [6].

When toxicity prevention methods are considered, in our study and the study conducted by Sağır et al., negative aspiration was the preferred method [8]. In contrast, other protection methods were found to be preferred by Karasu et al. and Urfalioglu et al.'s studies [6,9]. The fact that negative aspiration can be applied immediately at the bedside and does not require an additional device or waiting time may be the cause of this finding. Also, the self-confidence of the EMPs was higher for LAST, and this may make them use prevention methods less.

In a study by Oksuz et al., $54.1 \%$ and $50.9 \%$ of dentists stated that they knew the LAs dose they used and the max dosage of LAs, respectively [7]. In our study, it was $66.9 \%$ and $58.4 \%$, respectively. Although the basic pharmacology courses of the medical and dental faculties are similar, the clinical training may be different. Also, dentists generally use small doses in a small area, and in Oksuz et. al.'s study, only $13 \%$ of them encounter LAST, which is less than EMPs [7].

The majority of the participants (73\%) stated that they did not discuss the risks associated with LAST with their patients, and they did not obtain informed consent before the procedure. If such communication were standardized, participants may have more knowledge and awareness of LAST symptoms and treatments. Also, not obtaining informed consent may lead to some medico-legal issues for the EMPs. In Patel et al.'s study, they found the procedure specific informed consents were higher $(56 \%)$ than our study, and they stated that the procedure-specific patient education was not sufficient in informed consent forms for lumbar puncture patients [14]. Similarly, in Shaker et al.'s study, they stated that the quality of informed consent was in an undesirable condition [15]. In the Gaeta et al.'s study, they reported that ED residents couldn't get formal training for informed consent [16]. We conclude that the EMPs' residency training may not be sufficient at 


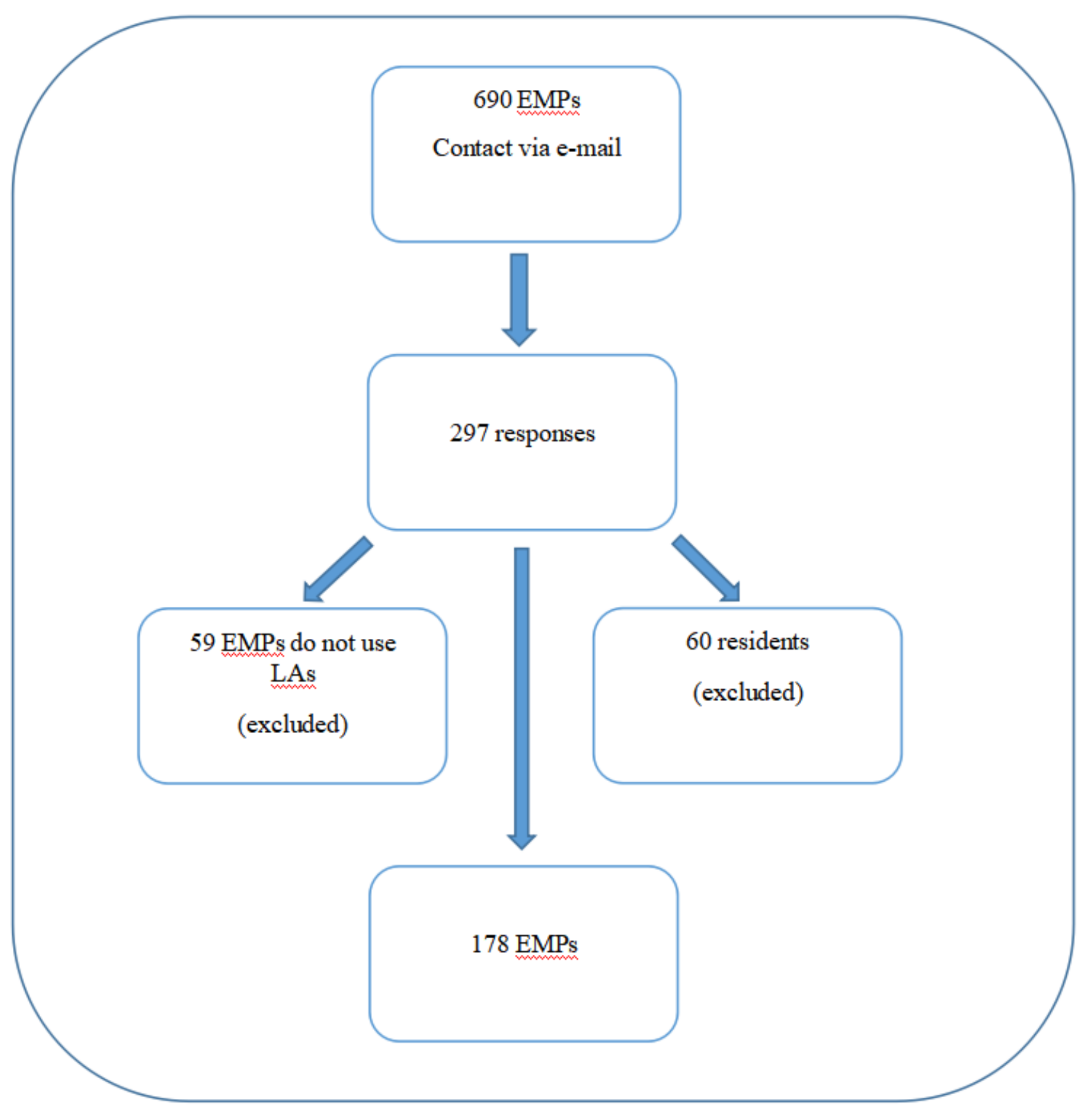

\section{F I G U RE 1. Flow diagram of the study.}

EMPs: Emergency medicine physicians, LAs: Local anesthetics.

highlighting the importance of informed consent.

The rate of participants who answered as "Never heard of ILE treatment" in Oksuz et al., Karasu et al. and Urfalıglu et al.'s studies were $67.3 \%, 67.4 \%$, and $65 \%$, respectively $[6,7,9]$. In our study, this rate was $3.9 \%$. We found, $42.1 \%$ of the respondents answered the treatment dose of ILE correctly, while this rate was found to be $3 \%$ in the survey conducted by Collins. We determined that ILE usage rates were higher than those compared to Urfalioglu et al.'s study [9]. These results can be explained by the frequent use of ILE therapy in LAST cases as well as other toxicity cases in ED practice. The constant education about ILE treatment in toxicology lessons also contributes to this result. The knowledge and awareness of EMPs about ILE treatment were higher than other specialties, but still low and disappointing.

\section{Conclusion}

The level of knowledge and awareness about LAST, which has high mortality and morbidity, is too low among EMPs. Compared to other studies in the literature, with other health care providers, the level of knowledge and awareness of EMPs in Turkey about LAST is higher, but still disappointing. Also, the self-confidence about LAST is higher. All physicians should inform patients about LAST before the procedure and take the 
necessary precautions and obtain informed consent. It should be ensured that the required training activities in all institutions are increased, and standardization and effectiveness of existing training programs are guaranteed. ILE should be present in all hospital pharmacies and used for the correct indications.

\section{Limitations}

This is a questionnaire-based study and depends on the participants' answers, with a large number of EMPs not responding. Also, the participants were using LAs primarily for minor procedures that need a lower dose. This may lead to less knowledge and awareness about toxicity. Also, this study aimed to evaluate the knowledge and awareness of EMPs on LAST and knowledge about LAs was not a primary focus.

\section{ACKNOWLEDGEMENTS}

The authors would like to thank ForEMS study group and EMAT Toxicology study group for their valuable support.

\section{CONFLICT OF INTEREST}

The authors declared no potential conflicts of interest with respect to the research, authorship, and/or publication of this article.

\section{AUTHOR CONTRIBUTIONS}

Buğra İlhan and Mehmet Cihat Demir designed the study. Buğra İlhan collected the data and Mehmet Cihat Demir analyzed the data. Buğra İlhan and Mehmet Cihat Demir analyzed the results and drafted the manuscript. Buğra İlhan and Mehmet Cihat Demir wrote and approved the final version of the manuscript.

\section{ETHICAL APPROVAL}

The ethics committee of the Bakırköy Dr. Sadi Konuk Training and Research Hospital approved the study (18.03.2019/2019143).

\section{AVAILABILITY OF DATA AND MATERIALS}

The data set used and analyzed during this study is available from the corresponding author on reasonable request.

\section{FUNDING}

The authors received no financial support for the research, authorship, and/or publication of this article.

\section{INFORMED CONSENT}

Written or electronic informed consent was obtained from each participant included in the study.

\section{HUMAN RIGHTS}

This manuscript was carried out in accordance with the Declaration of Helsinki and Good Clinical Practice guidelines.

\section{REFERENCES}

[1] Cave G, Harrop-Griffiths W, Harvey M, et al. AAGBI safety guideline: management of severe local anaesthetic toxicity. AAGBI. 2010.

[2] Neal JM, Barrington MJ, Fettiplace MR, et al. The Third American Society of Regional Anesthesia and Pain Medicine Practice Advisory on Local Anesthetic Systemic Toxicity: Executive Summary 2017. Reg Anesth Pain Med. 2018;43:113-123.

[3] Safety Committee of Japanese Society of A. Practical guide for the management of systemic toxicity caused by local anesthetics. J Anesth. 2019;33:1-8

[4] Dickerson DM, Apfelbaum JL. Local anesthetic systemic toxicity. Aesthetic surgery journal. 2014;34:1111-1119.

[5] Lee LA, Posner KL, Cheney FW,et al. Complications associated with eye blocks and peripheral nerve blocks: an American Society of Anesthesiologists closed claims analysis. Region Anesth Pain M. 2008;33:416-422.

[6] Karasu D, Yılmaz C, Özgünay ŞE, et al. Knowledge of the research assistants regarding local anaesthetics and toxicity. Turk J Anaesthesiol Reanim. 2016;44:201.

[7] Oksuz G, Urfalioglu A, Sekmen T, et al. Dentists knowledge of lipid treatment of local anaesthetic systemic toxicity. Niger J Clin Pract. 2018;21:327.

[8] Sagir A, Goyal R. An assessment of the awareness of local anesthetic systemic toxicity among multi-specialty postgraduate residents. J Anesth. 2015;29:299-302.

[9] Urfalığlu A, Urfalığlu S, Öksüz G. The knowledge of eye physicians on local anesthetic toxicity and intravenous lipid treatment: Questionnaire study. Turk J Ophthalmol. 2017;47:320.

[10] Collins J. Correspondence: awareness of local anaesthetic toxicity issues among hospital staff. Anaesthesia. 2010;65:960-961.

[11] Burillo-Putze G, Munne P, Duenas A, et al. National multicentre study of acute intoxication in emergency departments of Spain. Eur J Emerg Med. 2003;10:101-104.

[12] Koylu R, Dundar ZD, Koylu O, et al. The experiences in a toxicology unit: a review of 623 cases. J Clin Med Res. 2014;6:59-65.

[13] Annual report on the state of the drugs problem in Europe. European Monitoring Centre for Drugs and Drug Addiction (EMCDDA) L, November 2010. accessable on: https://www. emcdda. europa.eu/ publications/annual-report/2010_en .

[14] Patel PB, Anderson HE, Keenly LD, et al. Informed consent documentation for lumbar puncture in the emergency department. West J Emerg Med. 2014;15:318-24.

[15] Shaker SH, Hosseini Kasnavieh SM, et al. A Survey of Current Practice of Informed Consent in Iranian Hospitals. Hosp Top. 2018;96:69-74.

[16] Gaeta T, Torres R, Kotamraju R, et al. The need for emergency medicine resident training in informed consent for procedures. Acad Emerg Med. 2007; 14:785-789.

How to cite this article: Buğra ILHAN, Mehmet Cihat DEMİR. Knowledge of Local Anesthetic Systemic Toxicity among Emergency Medicine Physicians: A Cross-Sectional Study. Signa Vitae. 2020;16(2):148-154. doi:10.22514/sv.2020.16.0040. 